\title{
AN IMPROVED APPROACH TO DETECT FOREST FIRES AND TO PREDICT THE SPREAD DIRECTION OF FIRE USING WIRELESS SENSOR NETWORK
}

\author{
Purushottam S. Jadhav \\ PhD Scholar, ECE Department, \\ Bharath Institute of Higher Education and Research, Chennai, Tamilnadu, India.

\section{Dr. E. Kanniga} \\ Professor and Head, E\&I Department, \\ Bharath Institute of Higher Education and Research, Chennai, Tamilnadu, India
}

\begin{abstract}
Wireless Sensor Networks (WSNs) are used for forest fire detection. WSN comprises huge number of Sensor nodes which can be deploy in dense forest. Sensor Nodes are self configured and communicate with each other and forms network for sharing gathered information. Each node senses environmental changes, physical parameters with help of sensor and send this collected data to other neighboring nodes in the network. In this paper we have assembled three Sensor Nodes, one Master Node and other two are Slave Node. Each Node is having three sensors for measurement of temperature, humidity and smoke detector also for communication between Master and Slave Zigbee Transceivers module is used. With the help of Graphical User Interface in VB we get the data from different Nodes and this data is useful to detect the fire.
\end{abstract}

Keywords: WSN, Sensor Node, LM35, Humidity sensor, Smoke Detector, Zigbee

Cite this Article: Purushottam S. Jadhav and Dr. E. Kanniga, An Improved Approach to Detect Forest Fires and to Predict the Spread Direction of Fire Using Wireless Sensor Network, International Journal of Advanced Research in Engineering and Technology (IJARET), 11 (1), 2020, pp 70-79.

$\mathrm{http} / / /$ iaeme.com/Home/issue/IJARET?Volume $=11 \&$ Issue $=1$

\section{INTRODUCTION TO WSN}

A wireless sensor network is an infrastructure comprised of sensing, computing and communication elements that allows the administrator to monitor and control of the specified parameters in the network. Typical application of WSN includes data collection, monitoring, surveillance and medical telemedicine. Wireless Sensor Networks comprises independent sensor nodes which are able to communicate with each other by sensing different physical 
parameters within network, a single node cannot do this work, and they use wireless communication to enable this collaboration.

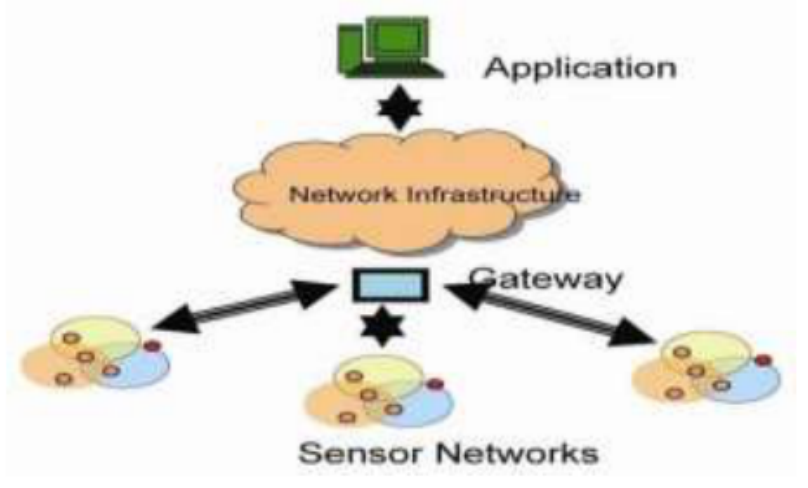

Figure 1 Structure of Wireless Sensor Network

Figure1 shows Structure of Wireless Sensor Network. Typical Wireless Sensor Network consists of following major components

Sensor Field: Sensor field can be considered as the area in which the nodes are placed.

Sensor Nodes: Nodes are the heart of the network. Sensor Nodes collects the data with the help of sensors and that information is routed to Sink Node.

Sink: A Sink Node receives data from different Sensor Nodes with specific task of receiving data, processing, analyzing and storage of data from other sensor.

This paper describes the method for detecting the forest fire. The proposed architecture is portioned into modules, each of which deals with various responsibilities of the overall system. In this paper, we discuss the method detect the forest fire with wireless sensor networks, which is deployed in a sensor field for detection of forest fire. Low power sensor network sense the physical parameters through wireless sensor nodes equipped with different sensors. Sense data is send to the base station or control room. This data is analyzed at base station / control room and proper action will take after receiving data.

\section{BLOCK DIAGRAM OF THE SYSTEM}

This system consists of three sensor nodes, two are the slave nodes and one is the master node which communicates with the base station as shown below. Block diagram consist of Sensor Node and Base Station

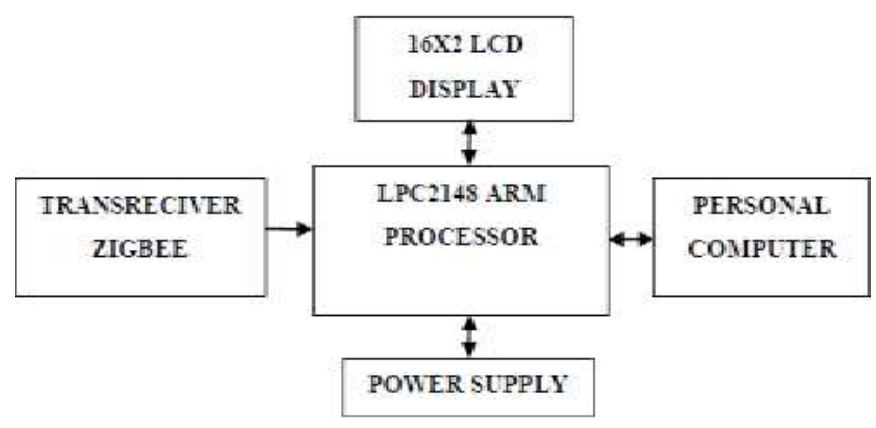

Figure 2: Block Diagram of System 


\subsection{Wireless Sensor Node}

ARM LPC 2148, 16-bit processor running $12 \mathrm{MHz}$ with $3.3 \mathrm{~V}$ battery is used to control sensor node. It utilizes a Chip on CC2420 RF transceiver radio operating at $2.4 \mathrm{GHz}$ ISM band for communications and three connectors for sensors. In this paper, we present Forest fire Monitoring System with wireless sensor networks, which are deployed in forest for forest fire monitoring. Low power sensor network measures physical parameters like temperature, humidity and smoke detection through wireless sensor nodes equipped with different level sensors. Measured data by the sensors and the data is send to the base station or control room. Appropriate action will be taken by base station/control room which depends on received data. The below figure shows how to monitor forest fire in the forest using temperature and humidity sensor and smoke detector and send the slave node data to master node for data logging at base station.

\subsection{Single Slave Node}

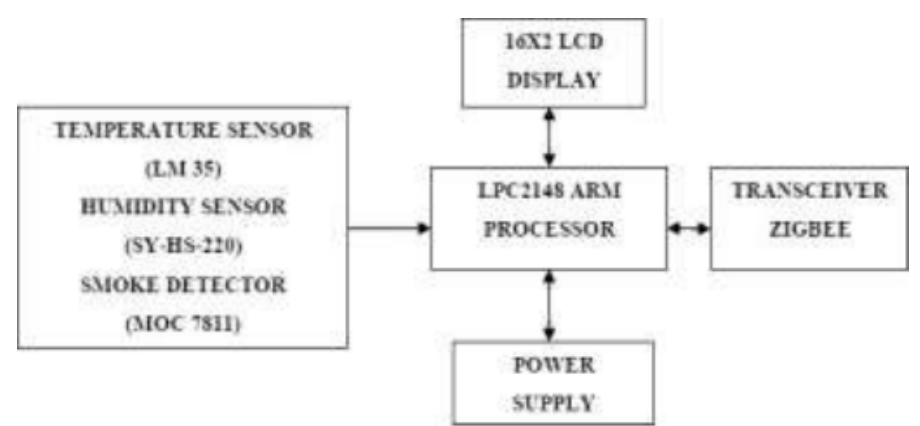

Figure 3: Single Slave Node

It consist of single sensor used to measure the temperature, humidity and smoke detection along with the processor as LPC 2138, 16x2 LCD display with RF Zigbee.

\section{FOREST FIRE SENSOR}

There are different sensors which are used for detection of parameter such as

\subsection{Temperature Sensor (LM35)}

Temperature sensor LM35 is sensor series with precision Integrated circuit. The main advantage of this sensor is that output voltage is linearly proportional to temperature in centigrade. This sensor does not require external calibration / trimming to obtain accuracies of $\pm 1 / 4{ }^{0} \mathrm{C}$ at room temperature and $\pm 3 / 4{ }^{0} \mathrm{C}$ over the range of $-55^{0} \mathrm{C}$ to $+150^{0} \mathrm{C}$ temperature range. For calibration/trimming it requires less cost. Another advantage of LM35 is linear output; less output impedance and precise inherent calibration make interfacing to readout or control circuitry especially easy. Single Power supply can be used, LM35 draws only $60 \mu$ A current from power supply also it has very low self-heating effect less than $0.1{ }^{\circ} \mathrm{C}$ in open air. The LM35 is rated to operate over a $-55^{\circ}$ to $+150^{\circ} \mathrm{C}$ temperature range, The LM35 series is available packaged in the plastic TO-92 transistor package 
An Improved Approach to Detect Forest Fires and to Predict the Spread Direction of Fire Using Wireless Sensor Network

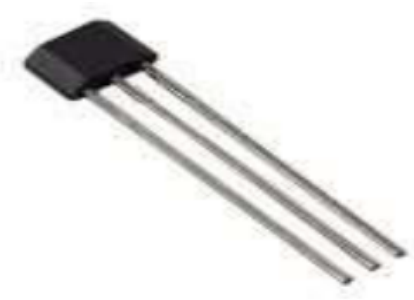

Figure 4: Temperature Sensor (LM 35)

\subsection{Humidity Sensor (SY-HS-220)}

Humidity is the moister content in the atmosphere, $0 \%$ relative humidity means totally dry atmosphere,

Rated Voltage - DC 5 V Operating Range - 30 to $90 \%$ RH

Standard output -DC1.98mV (at $25^{\circ} \mathrm{C} 60 \% \mathrm{RH}$ )

Accuracy -- $\pm 5 \%$ RH Rated Power -- $\leq 3 \mathrm{nA}$

Storage Temperature --30 to $85^{\circ} \mathrm{C}$

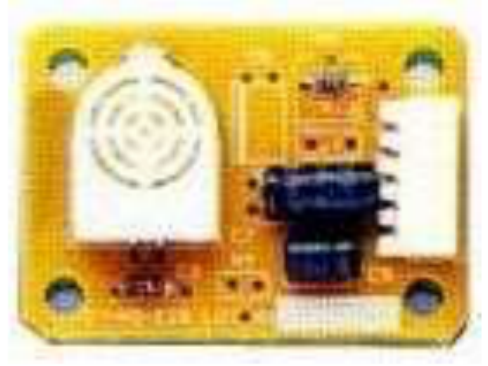

Figure 5 Humidity Sensor (SY-HS-220)

\subsection{Smoke Detector (MOC7811)}

Smoke detector is used to detect the smoke (carbon particles) which indication of fire. An optical detector is a light sensor. Smoke detector consists of light source (IR LED), a lens to collimate the light, and a photoelectric sensor (Photodiode) at an angle to the beam as light detector. If smoke is not present, the beam of light passes in a straight line. If smoke is present its small particles enters in smoke chamber across the path of beam of light, some light is scattered due to small particles, directing it at the sensor. The smoke detector is also known as Slotted coupler or Interrupted Module which comprises IR LED as a photo detector and is molded plastic housing between emitter and the photo detector which provides a means of interrupting signal.

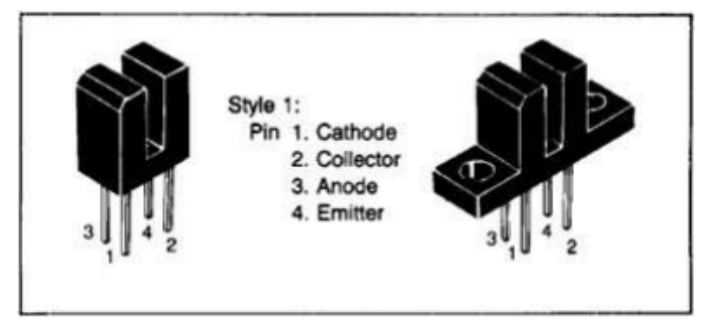

Figure 6: Smoke Detector (MOC 7811) 


\section{ZIGBEE}

The concept of Zigbee is related with erratic, zigzagging movements of bees between flowers while collecting pollens from the flowers. This type of pattern symbolizes communication between sensor nodes in a Zigbee networks. The network components are analogous to queen bee, drones, and worker bees. Zigbee network more useful than Wi-Fi or Bluetooth network because of some limitation. The advantages of Zigbee networks are very low cost, low power consumption, self-organizing, two ways, wireless communication protocol. It adopts IEEE 802.15.4, as its lower protocol layers: the Physical layer and Medium Access Control portion of Data Link Layer takes care of network, security and upper application issues. Zigbee system uses cell phone like radio links, using point to point or point to multipoint transmission. Zigbee overcomes drawbacks of traditional wireless formats like rigid structure, signal draping and meticulous planning.

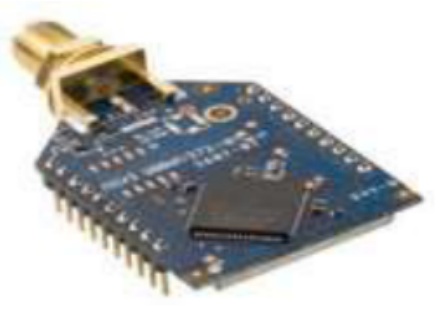

Figure 7: Zigbee Module

Zigbee network works on IEEE 802.15.4 standards which specifies for personal area networks Zigbee technology have advantages feature like low cost, low power consumption, low data rate in ad-hoc self-organizing network also it avoids range and obstruction issues.

\subsection{Base Station with Master Node}

Master node consists of processor as LPC 2138, 16x2 LCD display with RF Zigbee device. Base station act as a Personnel computer used to interface GUI-Graphical User Interface to monitor various forest fire levels with the day wise database is stored in Visual Basic for backend.

\subsection{Schematic of Slave Node}

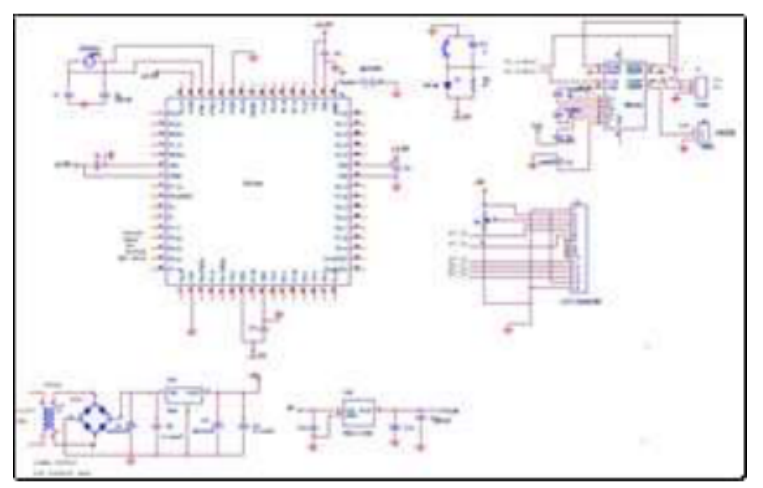

Figure 8 Schematic of Node

\section{SYSTEM SOFTWARE}

This topic gives the list of software's used in paper design which includes the schematic, PCB software's and compilers. As well as the algorithm and flow chart used for programming of paper. Following are the software's used 
An Improved Approach to Detect Forest Fires and to Predict the Spread Direction of Fire Using Wireless Sensor Network

Schematic Design: PROTEL

PCB Design: ORCHAD

Compiler: Kiel UVision-3

\subsection{Algorithm - Polling}

Below steps indicate the how algorithm for master and slave node is designed the protocol designed for the paper is based on POLLING architecture. Polling is a making continuous request for data from another device. In the Master and slave system, the master send quires to slave whether slave have any data to transmit or receive and if slave acknowledges yes then device transmit data. If slave acknowledges no then master moves on and polls the next slave node. The process is repeated continuously.

\subsection{For Master Node}

- Initialize the master node

- Request to slave for communication

- Acknowledge received

- Collect data from Slave

- Send to Com Port for GUI and Database

- Repeat the process.

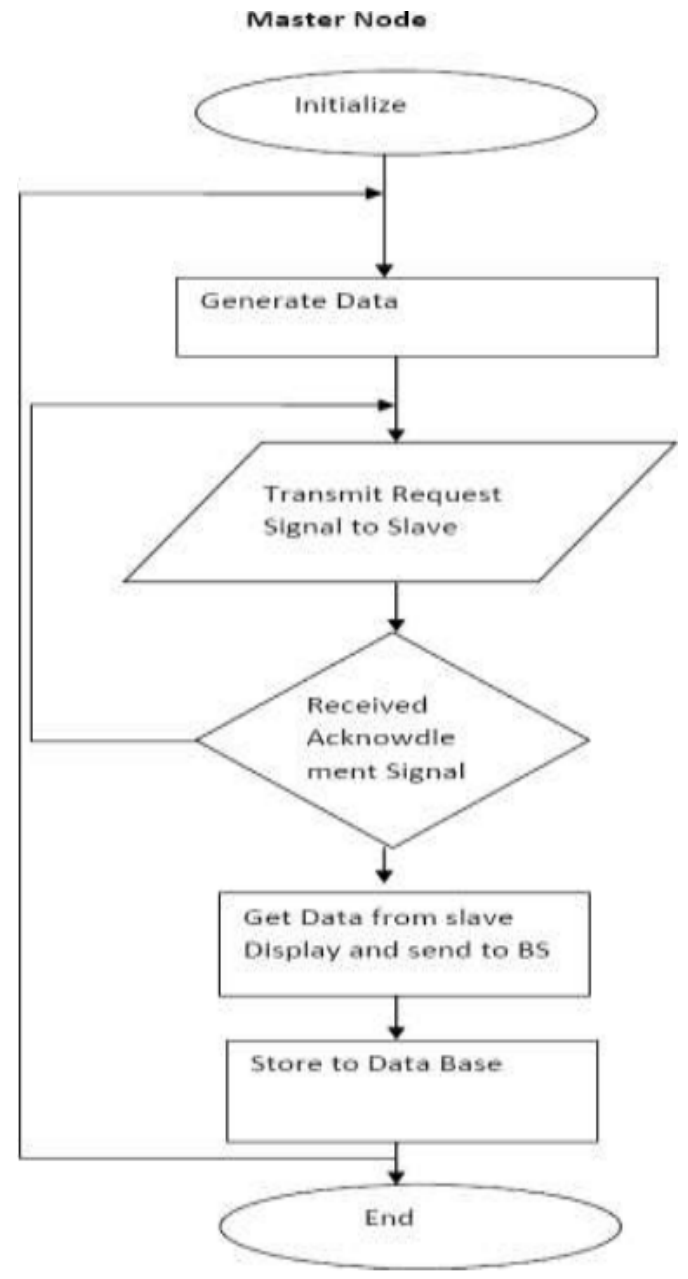

Figure 9 Master node flowchart 


\subsection{For Slave Node}

- Initialize the slave node

- Continuously read the data from sensor

- Wait for request from master

- Request received from master for communication

- Data from flood sensor transmit to master

- Display on LCD

- Repeat the process.

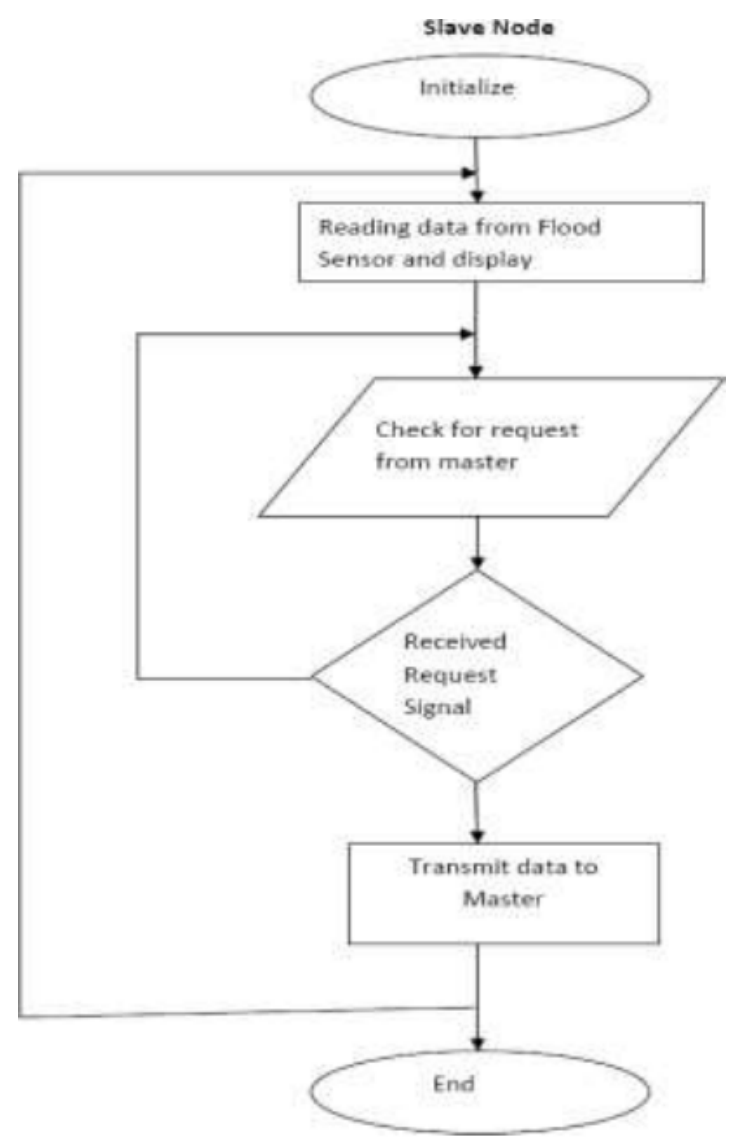

Figure 10: Slave node flowchart

\section{RESULTS}

The figure shows the status of the devices when data is sensed from forest. The reading for temperature, humidity and smoke detection is shown on the LCD display.

The figure 11 below shows the actual photo of three nodes with sensors. In the designed system WSN Node1 and WSN Node 2 sense the real time data is transmitted towards Master Node and then transmitted to base station. Whole data is recorded in Database at Base Station. The screen shots of VB are shown below. 
An Improved Approach to Detect Forest Fires and to Predict the Spread Direction of Fire Using Wireless Sensor Network

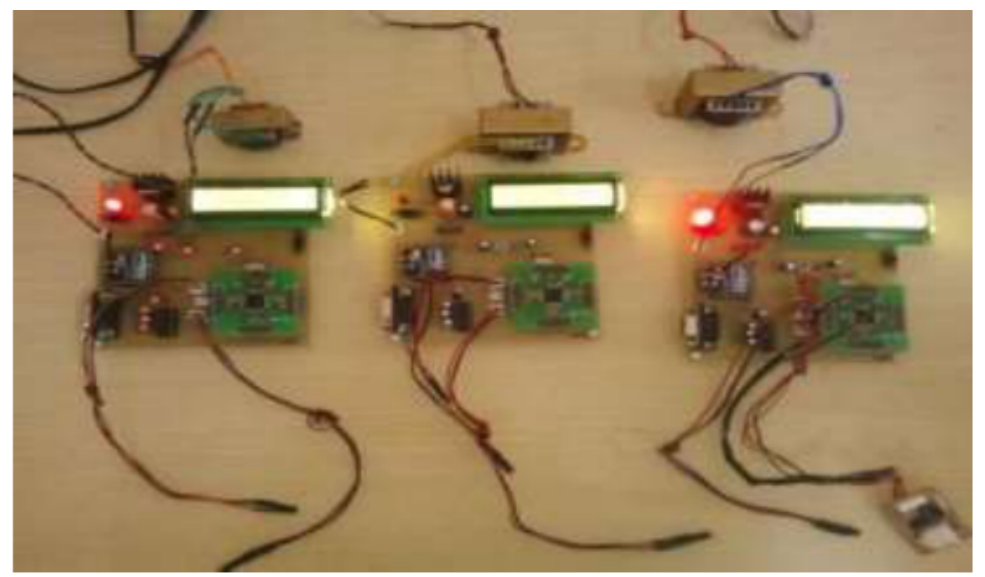

Figure 11: Actual photo of three nodes withsensors. reading.

The figure 11 shows the actual snapshot front end graphical user interface shows the

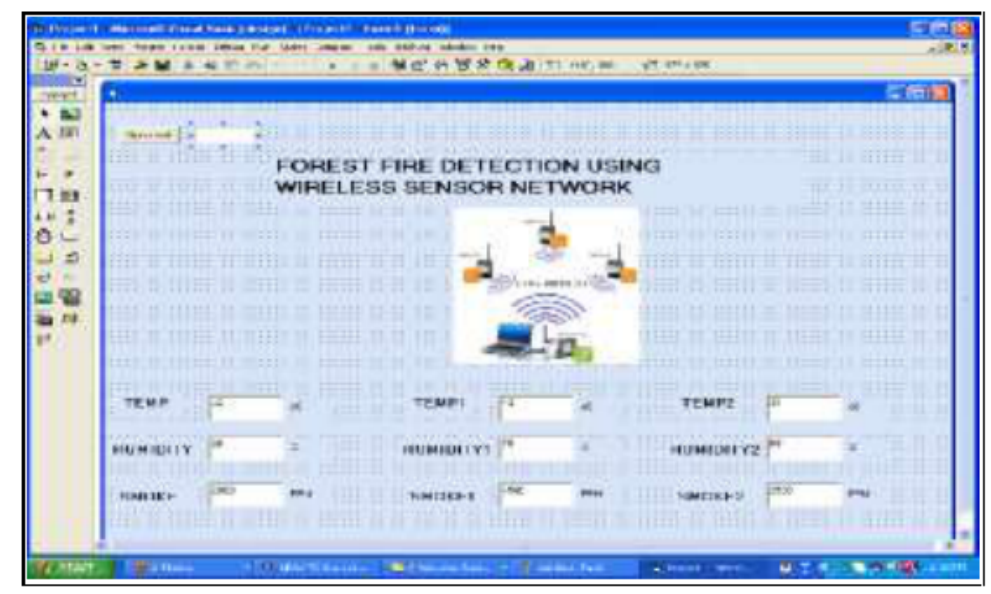

Figure 12: Graphical User Interface in VB

The figure 13 shows the actual snapshot back end graphical user interface shows the reading of as per day wise.

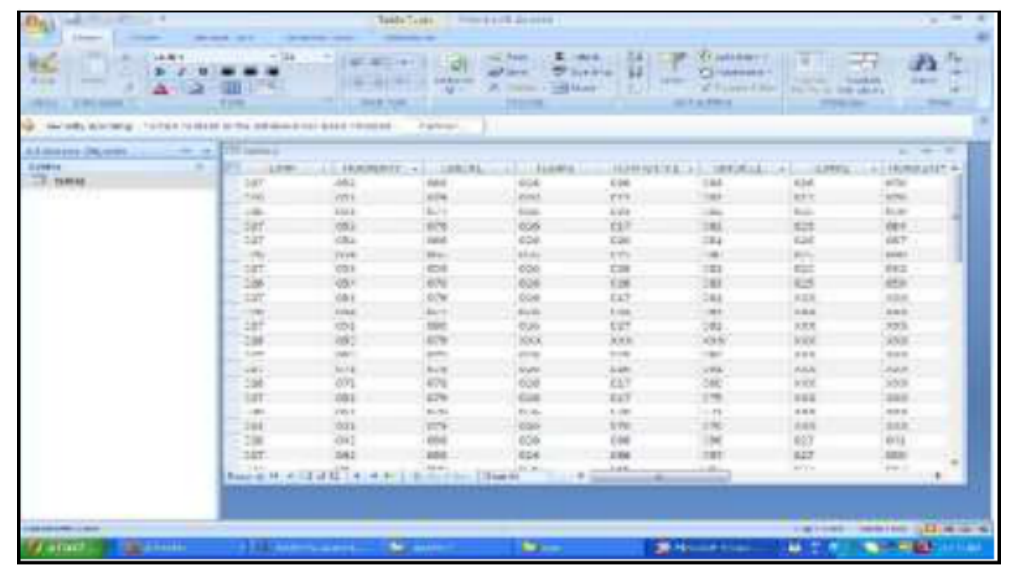

Figure 13: Day wise database in VB 


\section{CONCLUSION AND FUTURE SCOPE}

We introduced a WSN which is capable of detecting and monitoring forest fires based on smoke detection and temperature sensors. The network is created in a simple, star topology and due to this the computation and power demand is kept low. Additionally low-power, low cost hardware is used, this results in a flexible and easy-to implement sensor network. WSNs are designed for specific applications like environment monitoring, surveillance system, Industrial machine monitoring and military for target tracking systems. Each application differs infeatures and requirements. The forest fire detection using wireless sensor network can be done. The sensors or nodes are placed at different locations and the environmental parameters of that locations are measured. So WSN is an alternate way between human and nature, which extends human's ability to understand the nature.

\section{REFERENCES}

[1] Evizal Abdul Kadir, Sri ListiaRosa, Ana Yulianti 'Application of WSNs for Detection Land and Forest Fire in Riau Province Indonesia'978-1-5386-5721-8/18,ICECOS-2018, IEEE

[2] Lin K, Zhao H. "Energy Prediction and Routing Algorithm in Wireless Sensor Network" [J].Journal on Communications, 2006, 27(5):21-23.

[3] Rodoaplu V, Meng TH. 'Minimum Energy Mobile Wireless [J].IEEE J. Select. Areas Communications, I 999, 17(8):1333-1334.

[4] Zhou Yiming, Yang Xianglong "A Design of Greenhouse Monitoring and Control System Based Zigbee WSN” Hangzho, China, 978-1-4244-1312-5/07/, 2007IEEE

[5] Mohamed Yacoab, Mohemmed Shaand Mohamed Mustaq Ahmed, Secured Data Aggregation using Fibonacci Numbers and Unicode Symbols for WSN, International Journal of Computer Engineering and Technology, 10(1), 2019, pp. 218-225

[6] C. Tellez, O, Rodriguez and C. Lozano, 'Biomedical Signal Monitoring using Wireless Sensor Network', LATINCOM '09. IEEE Latin - American Conference on Communications, 2009.

[7] I. F. Akyildiz, W. Su, Y. Sankarasubramaniam, and E. Cayirci, "A Survey on Sensor Networks”, IEEE Comm. Mag., vol. 40, Issue 8, 102-114, August2002.

[8] K. Akkayaand M. Younis, "A Survey on Routing Protocols for Wireless Sensor Networks", Elsevier Ad Hoc Networks J., vol. 3, Issue 3, 325- 349, May2005.

[9] R. Shorey, A. Ananda, and W. T. Ooi, "Mobile, Wireless, and Sensor Networks," 1" Edition IEEE2006

[10] Y. Nikhita, K. Venkatesh, Gandharba Swain and S. Vinay Kumar Reddy, A Pre-Emptive Multiple Queue Based Congestion Control Algorithm for WSN. International Journal of Computer Engineering \& Technology, 8(2), 2017, pp. 49-54

[11] W. R. Heinzelman, A. Chandrakasan, and H. Balakrishnan, 'Energy Efficient Communication Protocol for WSN' Hawaii International Conf. on System Sciences Island of Maui, January2000.

[12] C. K.L. Lee, X.H. Lin, and Y.K. Kwok, 'A Multipath Ad-hoc Routing Approach to Combact Wireless Link Insecurity’, Proc. ICC 2003, vol. 1,448.

[13] Annu Joshi, Anup Bhola and G.N. Purohit, Integrated Approach to Defend Jamming Attack in WSN. International Journal of Computer Engineering and Technology, 9(3), 2018, pp. 148-158 
An Improved Approach to Detect Forest Fires and to Predict the Spread Direction of Fire Using Wireless Sensor Network

[14] B. Krishnamachari, S. Wicker, "Modeling Data Centric Routing in Wireless Sensor Networks" in Proceedings of IEEE INFOCOM, New York, June2002

[15] Jian Wam, Daxi Wang,"Design of Wireless Sensor Network Management System Based on Zigbee Technology "School of Computer Science and Technology, Hangzhou, China., 978-1-4244-5074-6/10/, 2010IEEE

[16] Durghadevi P, N. Vetrivelan, An Efficient LWSP Technique in WSN with Shortest Path Routinf for Less Latency in Data Transmission, International Journal of Computer Engineering and Technology10(3), 2019, pp.145-153

[17] Pritam Shah, Tahir Shaikh, Swati Shilaskar "Power Management using ZigBee Wireless Sensor Network "Vishwakarma Institute of Technology, Pune, India, 978 1-769532677608/\$ 25, 2008 IEEE

[18] N. Bulusu, J. Heidemann, and D. Estrin. 'GPS less Low Cost Outdoor Localization for very Small Devices’ IEEE Personal Communications, 7(5):28-34, 2000. 